\title{
Similar head impact acceleration measured using instrumented ear patches in a junior rugby union team during matches in comparison with other sports
}

\author{
Doug A. King, PhD, ${ }^{1}$ Patria A. Hume, PhD, ${ }^{1}$ Conor Gissane, $\mathrm{PhD},{ }^{2}$ and Trevor N. Clark, $\mathrm{MSc}^{3}$ \\ ${ }^{1}$ Sports Performance Research Institute New Zealand, School of Sport and Recreation, Faculty of Health and Environmental \\ Sciences, Auckland University of Technology, Auckland, New Zealand; ${ }^{2}$ School of Sport, Health and Applied Science, St \\ Mary's University, Twickenham, Middlesex, United Kingdom; and ${ }^{3}$ Australian College of Physical Education, Faculty of Sport \\ Performance, Sydney Olympic Park, New South Wales, Australia
}

OBJECTIVE Direct impact with the head and the inertial loading of the head have been postulated as major mechanisms of head-related injuries, such as concussion.

METHODS This descriptive observational study was conducted to quantify the head impact acceleration characteristics in under-9-year-old junior rugby union players in New Zealand. The impact magnitude, frequency, and location were collected with a wireless head impact sensor that was worn by 14 junior rugby players who participated in 4 matches.

RESULTS A total of 721 impacts $>10 \mathrm{~g}$ were recorded. The median (interquartile range [IQR]) number of impacts per player was 46 (IQR 37-58), resulting in 10 (IQR 4-18) impacts to the head per player per match. The median impact magnitudes recorded were $15 \mathrm{~g}(\mathrm{IQR} 12 \mathrm{~g}-21 \mathrm{~g})$ for linear acceleration and $2296 \mathrm{rad} / \mathrm{sec}^{2}\left(\mathrm{IQR} 1352-4152 \mathrm{rad} / \mathrm{sec}^{2}\right)$ for rotational acceleration.

CONCLUSIONS There were 121 impacts (16.8\%) above the rotational injury risk limit and $1(0.1 \%)$ impact above the linear injury risk limit. The acceleration magnitude and number of head impacts in junior rugby union players were higher than those previously reported in similar age-group sports participants. The median linear acceleration for the under9-year-old rugby players were similar to 7- to 8-year-old American football players, but lower than 9- to 12-year-old youth American football players. The median rotational accelerations measured were higher than the median and 95th percentiles in youth, high school, and collegiate American football players.

http://thejns.org/doi/abs/10.3171/2015.12.PEDS15605

KEY WORDS injury; linear; rotational; impact; rugby union; wireless head impact sensor; trauma

$\mathrm{S}$ PORTS-related concussion has received increased media and public awareness with concern for player safety and the risk of injury. ${ }^{6,10,37}$ Knowledge about the potential metabolic and ultrastructural consequences of impacts to the head has grown, as has the appreciation for repetitive concussive and subconcussive impacts and the possible deleterious effects in some individuals. ${ }^{37}$ Using technology, such as accelerometers in the helmets of American football players, ${ }^{4,9,10}$ has increased knowledge of the injury biomechanics of the forces, accelerations, frequencies, and velocities of head injuries. ${ }^{37}$ This knowledge can be applied to reduce the circumstances where head injuries can occur.
Youth football players are physically smaller in stature and body mass, ${ }^{23}$ have a lower impact velocity, and participate less than older senior rugby players. ${ }^{37}$ However, the risk of a concussive injury, from impacts during sports activities such as football, is higher for younger players when compared with adults. ${ }^{11}$ As well as a higher risk of a concussive event, younger players can also have a prolonged recovery process when compared with adults. ${ }^{12} \mathrm{In}$ American youth football (6- to 9-year-old players) there was a reported average of 107 impacts per player per season, with an average linear and rotational acceleration of $18 \mathrm{~g}$ and $901 \mathrm{rad} / \mathrm{sec}^{2}$. Most impacts occur during practice (59\%) and have a higher magnitude than those recorded in

ABBREVIATIONS HITS = Head Impact Telemetry System; IQR = interquartile range; K-D = King-Devick; PLA = peak linear acceleration; PRA = peak rotational acceleration.

SUBMITTED October 9, 2015. ACCEPTED December 28, 2015.

INCLUDE WHEN CITING Published online March 4, 2016; DOI: 10.3171/2015.12.PEDS15605. 
matches..$^{10}$ In Pop Warner "Junior Midgets" football players (12- to 13-year-old players), 480 impacts were recorded during matches with an average linear acceleration of $47 \mathrm{~g}$ $\pm 14 g .{ }^{37}$ This was slightly higher than middle school football players (12 to 14-year-old players), where the match average linear acceleration was $21 g \pm 3 g \cdot{ }^{11}$ Although youth players are smaller and had fewer head impacts than older players, they recorded higher magnitude impacts. The long-term implications of head impacts in an exposure paradigm are unknown. ${ }^{37}$

Nonhelmeted sports have also used accelerometers to measure impacts in sports participation. Heading the ball by female soccer youths yielded peak accelerations of $63 \mathrm{~g}$ and $8869 \mathrm{rad} / \mathrm{sec}^{2} .^{18}$ No concussions were reported, ${ }^{18}$ as no injury or injury risk was assessed, even though some of the rotational accelerations were within the nominal values for an injury to the head when compared with National Football League data ${ }^{33}$ and injury risk tolerance levels. ${ }^{40}$ Although data are accumulating for soccer and the National Football League, there are no published data for nonhelmeted collision sports such as the junior rugby union. The objective of this explorative study was to investigate the head impact acceleration characteristics via wireless head impact sensors during 4 matches in junior rugby union players in New Zealand.

\section{Methods}

A prospective observational cohort study was conducted on a junior rugby union team during 4 consecutive matches in a 2015 competition in New Zealand. The matches were played under the rules of the New Zealand Rugby Football Union for the under-9-year-old group. The protocol was approved by the Auckland University of Technology ethics committee, and all of the players' parents provided informed consent before participating in the study. The study participants were $8.4 \pm 0.6$ years of age and had no injuries at the start of the study that would have affected their participation in rugby.

Players wore the XPatch impact-sensing skin patch (X2Biosystems Ltd.) on the skin covering their mastoid process (right side) during each match. The XPatch sensor samples at $1024 \mathrm{~Hz}$ and was placed behind the player's right ear just before participation in match activities and was removed immediately after the match was completed. The positioning of the XPatch over the mastoid process was important to ensure that the sensor was not activated by enhanced soft-tissue effects when impacts occurred. ${ }^{38}$

The XPatch contained a low-power, high- $g$, triaxial accelerometer with $200 \mathrm{~g}$ maximum per axis and a triaxial angular rate gyroscope that was used to capture 6 degrees of freedom for the linear and rotational accelerations over time of the head's center of gravity for all impacts that occurred during match participation. The time history incorporated 3 axes $(x, y, z)$ of acceleration and 3 axes of velocity. Standing in an upright position, these planes describe the medial-lateral, anterior-posterior, and vertical acceleration and deceleration, respectively.

The XPatch has a strong correlation with peak linear acceleration (PLA; $\left.r^{2}=0.93\right)^{38}$ with a normalized root square error of $18 \%$, but may overpredict PLA and peak rotational acceleration (PRA) by $15 g \pm 7 g$ and $2500 \pm$ $1200 \mathrm{rad} / \mathrm{sec}^{2}$, respectively. Nevins et al. ${ }^{30}$ reported that the XPatch had good agreement with PLA but underestimated PRA by more than $25 \%$. The XPatch also has a significantly statistical correlation with the Head Impact Telemetry System (HITS) for the resultant linear $(r=0.44$; $\mathrm{p}<0.001)$ and rotational $(r=0.15 ; \mathrm{p}<0.001)$ accelerations and for the Head Impact telemetry severity profile $(r$ $=0.34 ; \mathrm{p}<0.001) .{ }^{25}$ If an accelerometer exceeded the predetermined $10 \mathrm{~g}$ linear acceleration threshold, $100 \mathrm{msec}$ of data (10 msec pre-trigger and $90 \mathrm{msec}$ post-trigger) from each accelerometer and gyroscope were recorded to the on-board memory for later downloading. The $10 \mathrm{~g}$ linear acceleration threshold was chosen to identify impacts that were considered to have occurred from impact accelerations during rugby activities while eliminating activities undertaken in daily living, such as walking., 928 This data acquisition limit was based on a review of data acquisition limits used in previous studies. ${ }^{22}$

Following the match, the XPatch was removed from the player and the data were downloaded to the Injury Management Software (X2Biosystems), which enabled the raw accelerometer data to be transformed to the head's center of gravity by using a rigid-body transformation for linear acceleration and a 5-point stencil for rotational acceleration. ${ }^{22,38}$ The biomechanical measures of head impact severity consisted of impact duration (measured in milliseconds), linear acceleration $(g)$, and rotational head acceleration $\left(\mathrm{rad} / \mathrm{sec}^{2}\right)$. The resultant linear acceleration is the rate of change in the velocity of the estimated center of gravity of the head attributable to an impact and the associated direction of the motion of the head. ${ }^{29}$ The resultant rotational acceleration is the rate of change in the rotational velocity of the head attributable to an impact and its direction in a coordinate system with the origin at the estimated center of gravity of the head. ${ }^{29}$ False impacts were removed by the X2Biosystems's proprietary "de-clacking" algorithm ${ }^{22}$ by comparing the waveform of each impact to a "Gaussian-like" reference waveform using cross-correlation..$^{22}$ Impacts with a resultant linear acceleration of $<10 \mathrm{~g}$ were removed. The remaining impacts were downloaded to an Excel spreadsheet and timefiltered to include only those impacts that occurred during match participation.

Head impact exposure, including frequency, magnitude, and the location of impacts, were quantified using previously established methods ${ }^{8,9}$ Data were not collected at team trainings due to the low attendance at training by all players compared with matches. Two measures of impact frequency were computed for each player: 1) player impacts (including the total number, median 25 th to 75 th interquartile range [IQR], 95th percentile, and the cumulative number of head impacts recorded for a player during all observed matches); and 2) impacts per match (including the total number, median [IQR], 95th percentile, and the cumulative number of head impacts recorded for a player during all observed matches). Due to the age of the players and ethical considerations, video capture was not conducted on the matches; therefore, verification of the impacts in conjunction with video evidence was not possible. 
All filtered data on the Microsoft Excel spreadsheet were analyzed using SPSS (version 22.0.0). The impact variables were not normally distributed (KolmogorovSmirnov test; $p<0.001)$. Therefore, data were expressed as median (IQR) and as severity measures (95th percentile of linear acceleration and 95th percentile of rotational acceleration). ${ }^{20,21}$ Additionally, the cumulative impact burden per match and per player per match were analyzed using Kruskal-Wallis 1-way ANOVA with a Dunn's post hoc test for all pairwise comparisons. Although there is no accepted method for quantifying cumulative impact burden, ${ }^{2}$ the sum of the linear and rotational accelerations associated with each individual head impact over the course of the study was calculated for all of these parameters.

The impact location variables were computed as the azimuth and elevation angles relative to the center of gravity of the head centered on the midsagittal plane. ${ }^{7}$ These were categorized as front $\left(\theta=180^{\circ}\right.$ to $-135^{\circ}$ [left] and $\theta$ $=180-135^{\circ}$ [right $\left.]\right)$, side $\left(\theta=-135^{\circ}\right.$ to $-45^{\circ}$ [left] and $\theta=$ $135-45^{\circ}$ [right]), back $\left(\theta=-45^{\circ}\right.$ to $0^{\circ}$ [left] and $\theta=45^{\circ}$ to $0^{\circ}$ [right]) and top $\left(\theta=180^{\circ}\right.$ through negative $\theta$ to $0^{\circ}$ [left] and $\theta=180^{\circ}$ through positive $\theta$ to $0^{\circ}$ [right]). Impacts to the top of the head were defined as all impacts above an $\alpha$ value of $65^{\circ}$ from a horizontal plane through the center of gravity of the head..$^{16}$ Impact locations were analyzed as front, back, side, or top using a Friedman repeated-measures ANOVA on ranks.

Head impacts were assessed for the injury tolerance level for a concussion using previously published injury tolerance levels ${ }^{2,3,17}$ for linear $(>95 g)$ and rotational acceleration (> $\left.5500 \mathrm{rad} / \mathrm{sec}^{2}\right)$. Head impacts were assessed for impact severity using previously published levels for linear acceleration (mild $<66 g$, moderate $66 g-106 g$, and severe $>106 g$ ) and rotational acceleration (mild $<4600$ $\mathrm{rad} / \mathrm{sec}^{2}$, moderate $4600-7900 \mathrm{rad} / \mathrm{sec}^{2}$, severe $>7900$ $\left.\mathrm{rad} / \mathrm{sec}^{2}\right) \cdot{ }^{19,31,40}$ Both injury tolerance and impact severity levels were analyzed using Friedman repeated-measures ANOVA on ranks. Post hoc analysis with the Wilcoxon signed-rank tests was conducted with a Bonferroni correction applied. Statistical significance was set at $\mathrm{p}<0.05$.

Prior to the first match, the players completed a baseline King-Devick (K-D) test using 2 of the 3 test cards. The K-D test recommends using test cards 1 and 2 for players younger than 9 years. The K-D test is a rapid number-naming test that takes less than 2 minutes to administer. ${ }^{13,14}$ The K-D test involves the player reading aloud a series of random single-digit numbers from left to right. The K-D test includes 1 practice (demonstration) card, and the test cards varied in format on either a moisture-proof $6 \times 8$-inch spiral-bound physical test or as an application on a iPad platform. Players used the moisture-proof, $6 \times$ 8-inch, spiral-bound physical test to establish their baseline score. This was transferred to the iPad platform at the completion of the K-D test. The time was kept for each test card, and the K-D test summary score for the entire test was based on the cumulative time taken to read the test cards. The number of errors made in reading the test cards was recorded. The best time (fastest) of the 2 trials without errors became the established baseline K-D test time. ${ }^{13}$ When head trauma was suspected, the K-D test was used as a screening tool. The K-D test was administered once using the same instructions, and the time and errors were recorded and then compared with the participant's baseline.

The K-D test has been reported to have an interclass correlation for test-retest reliability of $0.96^{26}$ and $0.97 . .^{13}$ The K-D test has also been reported to have significant correlations $(\mathrm{p}<0.0001)$ with the visual motor speed, reaction time, verbal memory, and visual memory on the Immediate Postconcussion Assessment Cognitive Test ${ }^{35}$ computerized concussion evaluation system. The K-D tests used were v2.2.0 (http://www.kingdevicktest.com) on an iPad2. The iPad2 testing platform enables the use of the K-D test with 3 different number-set test versions, and these varied over the duration of the study in order to reduce possible learning effects. The parents of the youth players would bring their child to the tester in order to undergo the K-D test evaluation following any incident they considered to be an impact to their child's head.

All collected K-D data were entered into a Microsoft Excel spread sheet and analyzed using SPSS (version $22.0 .0)$. Data are presented as mean ( \pm standard deviation) for player data, concussive injury per 1000 match-hours with $95 \%$ confidence intervals and median (25th-75th interquartile range) for the K-D scores. Differences in K-D scores at pre-competition (baseline establishment) were calculated, and baseline and post-match K-D scores were compared using the Wilcoxon signed-rank test by the sporting code and combined composite score. The sensitivity and specificity of the K-D test was calculated using a $2 \times 2$ contingency table with 95\% CI and Cohen kap-

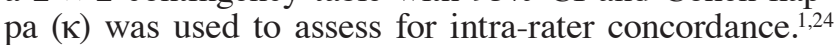
Test-retest reliability was also estimated by utilizing the intraclass correlation coefficient with 95\% CI to examine agreement between first and second baseline test scores and the post-study scores.

\section{Results}

Fourteen players participated in the 4 matches observed in this pilot study. There were 721 impacts to the head greater than $10 \mathrm{~g}$ (range $10 \mathrm{~g}-141 \mathrm{~g}$ ) recorded over the duration of the study (Table 1). The median (IQR) number of impacts per player over the evaluation period was 46 (IQR 27-58), resulting in 10 (IQR 4-18) impacts to the head per player per match with a duration of 6.0 (IQR 4.0-11.0) msec per impact.

The impact magnitudes were skewed to the lower values $(D=0.226$; $\mathrm{p}<0.001)$ with a median (IQR) acceleration of $15 g$ (IQR $12 g-21 g$ ). Rotational accelerations were also skewed to lower values $(D=0.172 ; \mathrm{p}<0.001)$ with a median (IQR) acceleration of $2296 \mathrm{rad} / \mathrm{sec}^{2}$ (IQR 1352$\left.4152 \mathrm{rad} / \mathrm{s}^{2}\right)$. There were 121 impacts $(16.8 \%)$ above the rotational injury risk limit and $1(0.1 \%)$ impact above the linear injury risk limit (Table 2 ).

The number of impacts to the areas of the head varied over the evaluation period (Table 2). The side of the head $(n=448)$ recorded the most impacts. The front of the head recorded the highest median resultant linear acceleration $(19 g)$ when compared with the top $(\mathrm{p}=0.008)$, side $(\mathrm{p}<$ $0.001)$, and back $(\mathrm{p}=0.008)$ of the head. The front of the head recorded the highest median resultant rotational ac- 
TABLE 1. Resultant linear and rotational accelerations of junior rugby union players for impacts $>10 \mathrm{~g}$

\begin{tabular}{lcccc}
\hline Motion Type & Total Recorded & Median (IQR) & 95th Percentile (IQR) & Median (IQR) Total Frequency Impact Burden* \\
\hline PLA, $g$ & 721 & $15(12-21)$ & $46(37-55)$ & $3411(3351-3605)$ \\
\hline PRA, rad/s & 721 & $2296(1352-4152)$ & $10,434(9297-10,760)$ & $595,624(585,834-599,359)$ \\
\hline
\end{tabular}

* Total impact frequency burden is the sum of all impacts in terms of linear and rotational accelerations.

celeration (4003 rad/ $\left./ \mathrm{sec}^{2}\right)$ when compared with the top (p $=0.008)$, side $(\mathrm{p}<0.001)$, and back $(\mathrm{p}=0.008)$ of the head.

There were observable learning effects between the first and second K-D test baseline testing (50.3 vs 46.8 seconds; $\mathrm{z}=-3.29 ; \mathrm{p}<0.0001)$ and baseline and poststudy (46.8 vs 45.5 seconds; $z=-2.02 ; p=0.0431$ ) (Table $3)$. There were no observed concussions over the duration of the study. Four players had a delay (i.e., worsening) in their K-D score times with a median (IQR) delay of 4.7 seconds (IQR 4.1-5.0 seconds) $(z=-1.83 ; \mathrm{p}=0.079)$ from their baselines scores. K-D testing demonstrated a sensitivity of 1.00 (95\% CI $0.48-1.00)$, specificity of 0.61 (95\% CI 0.39-0.81), and a $\mathrm{K}$ value of 0.36 (95\% CI 0.06-0.62).

\section{Discussion}

This study reports, for the first time, the head impact characteristics (frequency, magnitude, and location) experienced by a team of under-9-year-old junior rugby union players. By utilizing accelerometer-fitted patches worn behind the ear of each participant in a single junior rugby union team over 4 consecutive matches, there were 721 impacts recorded.

The 4 players who had a delay (worsening) in their K-D tests from their baseline values were withheld from further participation in the match, and the parents were advised to have their child examined medically in order to exclude a concussive injury. Three of the 4 players were diagnosed by a qualified health practitioner as having a concussive injury (players 1, 3 and 4) (Table 4) and underwent a medically supervised, return-to-sport, graduated, stepwise protocol. Player 2 was retested when he returned to play 2 weeks later and had returned to his baseline score. No player who had a decrease in K-D test recorded an impact over $67 g$ of resultant linear acceleration, but all of these players did record a resultant rotational acceleration over the $5500 \mathrm{rad} / \mathrm{sec}^{2}$ injury tolerance level. ${ }^{1,5,13}$

The under-9-year-old age group is where tackling is first introduced into match activities in New Zealand, and therefore tackling-related skills are developing. The current cohort experienced match participation head impacts with higher magnitudes $(>80 g)$ than expected. The magnitudes were similar to impacts reported in American high school ${ }^{3-5}$ and collegiate ${ }^{5,8,9}$ football players, but the New Zealand rugby union players were younger, had less body mass, and played at a slower speed than the American players. ${ }^{10,39}$ Unlike American football, rugby union does not have the same protective equipment worn during match activities.

Comparing impact data between studies can be difficult given the different thresholds used to count an impact. For example, the data acquisition limit used for recording impacts to the head in Pop Warner youth football ${ }^{37}$ players was any linear acceleration greater than $30 g$, while other studies used $10 g^{10}$ and $14.4 g^{6,11,39}$ limits. No rotational accelerations were reported in Pop Warner youth football. By using a $30 \mathrm{~g}$ data acquisition limit for Pop Warner football, approximately $80 \%$ to $85 \%$ of the impacts may have been excluded from the data set. ${ }^{37}$ Daniel et al. ${ }^{10}$ examined American football players aged 6 to 9 years, and approximately $85 \%$ of the impacts recorded had a linear acceleration below $30 \mathrm{~g}$. This was similar in 9- to 11-year-old American football players, with $80 \%$ of impacts recording linear accelerations below $30 g .{ }^{6}$ Unless the data were reported at the different data acquisition limits used in previous studies (i.e., $10 g,{ }^{10} 14.4 g,{ }^{1,6,21}$ and $30 g^{37}$ ), resulting in complex tables or large amounts of data presented, then interstudy comparisons are limited.

Although these published studies were included as comparisons with the current study, the comparisons should be undertaken with caution as the reported data acquisition limit used in the current study was set at $10 \mathrm{~g}$. A standardized reporting format for impacts needs to be established to identify what parameters should be included (i.e., resultant linear [PLA $(g)$ ] and rotational acceleration [PRA $\left(\mathrm{rad} / \mathrm{sec}^{2}\right)$ ], Head Impact Criterion (15 msec), Gadd Severity Index, Head Impact Telemetry severity profile) and at what linear data acquisition limit the data should be reported. The identification of thresholds for head impacts that are subconcussive versus non-subconcussive is needed.

In youth football (6-9 years old), players averaged 44 impacts during matches, or 5.8 impacts to the head per player per match..$^{10}$ This study had similar impacts to the current study with players recording a median of $46 \mathrm{im}-$ pacts to the head during matches but a higher median number of impacts (10) per player per match. In a slightly older youth football team (12-14 years old), ${ }^{11}$ players recorded an average of 112 impacts during matches, or 12 impacts per player per match. Although the numbers of impacts per player per match are similar, the total impacts per match were higher. Similar to other studies that report head impact biomechanics, the magnitudes recorded were characterized by a skewed frequency distribution with most (64\%) impacts having a linear acceleration of between $10 \mathrm{~g}$ and $20 \mathrm{~g}$. There were, however, 3 impacts recorded over the duration of the study that were above $80 \mathrm{~g}$. This magnitude has been previously described ${ }^{28}$ as "high" and highlights that youth players can be exposed to impacts over a competition that are considered high magnitude at any level of participation. Despite the number of high-magnitude impacts recorded, there were no witnessed concussive events recorded throughout the duration of the study.

Previous studies that reported the impacts for youth American football players have shown that the median 


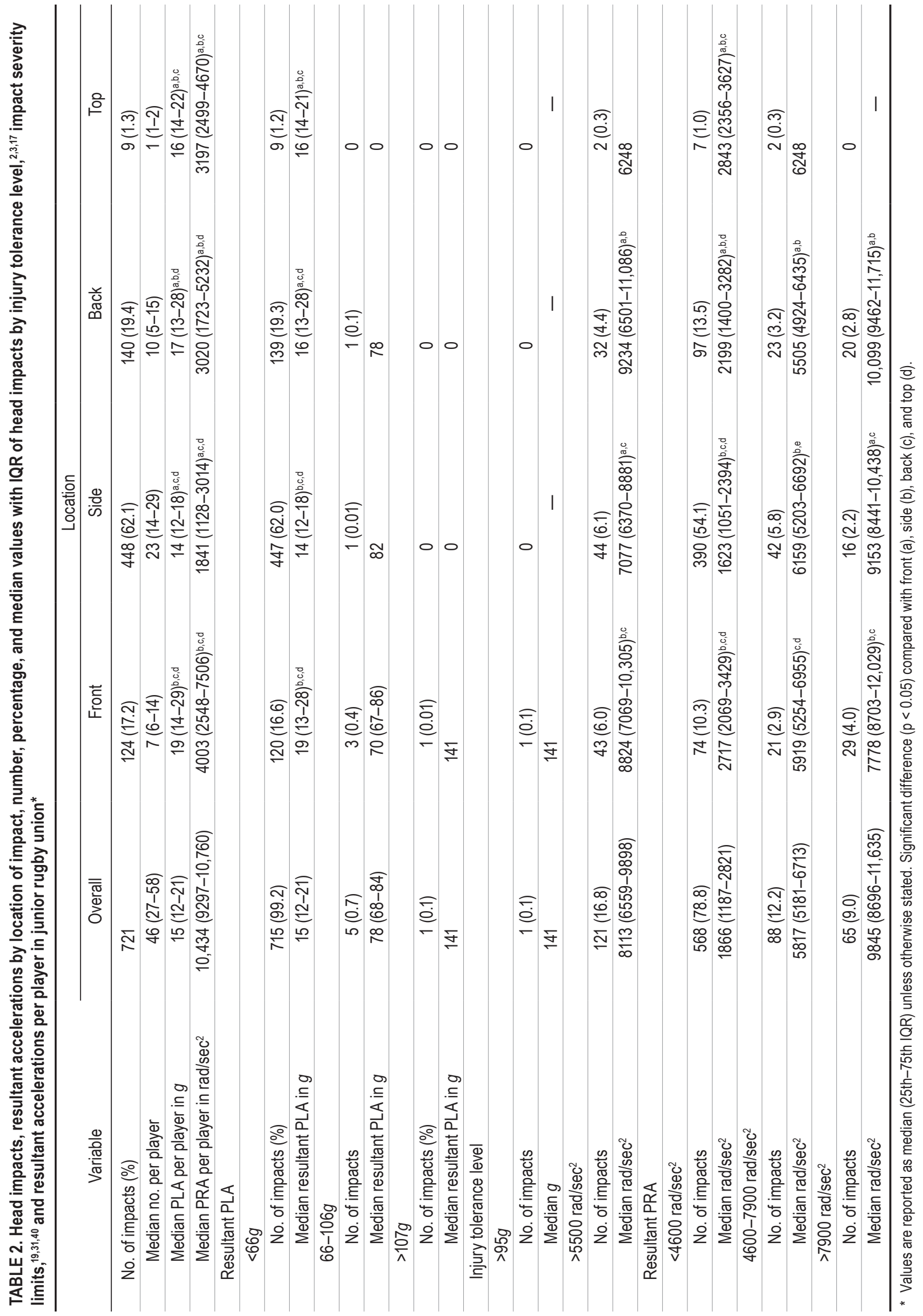


TABLE 3. Characteristics of the participants

\begin{tabular}{|c|c|}
\hline Characteristic & Value \\
\hline No. of players enrolled & 14 \\
\hline Mean age \pm SD in yrs & $8.4 \pm 0.6$ \\
\hline Matches played (match-hours) & $4(22.0)$ \\
\hline $\begin{array}{l}\text { Total no. of concussive incidents (witnessed; } \\
\text { unwitnessed) }\end{array}$ & $4(0 ; 4)$ \\
\hline $\begin{array}{l}\text { Concussion incidence per } 1000 \text { match-hours } \\
\qquad(95 \% \mathrm{Cl})\end{array}$ & $181.8(3.6-360.0)$ \\
\hline Median (IQR) preseason K-D test 1 , sec & $50.3(46.4-53.0)$ \\
\hline Median (IQR) preseason K-D test 2, sec & $46.8(40.0-50.0)^{*}$ \\
\hline Median (IQR) difference test 1 vs test 2 , sec & $-3.3(-4.1$ to -2.7$)$ \\
\hline Median (IQR) post-study K-D test, sec & $43.6(37.2-49.6) \dagger$ \\
\hline Median difference baseline vs postseason, sec & $-2.5(-5.8$ to -2.3$)$ \\
\hline ICC (95\% CI), K-D baseline 1 vs baseline 2 & $0.97(0.79-0.99)$ \\
\hline ICC $(95 \% \mathrm{CI}), \mathrm{K}-\mathrm{D}$ baseline vs postseason & $0.96(0.88-0.99)$ \\
\hline K-D test sensitivity $(95 \% \mathrm{Cl})$ & $1.00(0.48-1.00)$ \\
\hline K-D test specificity $(95 \% \mathrm{Cl})$ & $0.61(0.39-0.81)$ \\
\hline
\end{tabular}

recorded linear acceleration $(15 g)$ was lower when compared with other levels of participation. Observations of 7- to 8-year-old American football players ${ }^{39}$ showed a median linear acceleration of $16 \mathrm{~g}$, which was similar to the current study. This was lower than 9- to 12-year-old youth American football players with a median head impact of $18 g,{ }^{6}$ while 12 - to 14 -year-old players ${ }^{11}$ recorded a slightly higher median linear acceleration of $22 g$. Although it appears that the players in the current study may have a lower resultant linear acceleration than similarly aged American football players, this could reflect how these games differ. American football players wear full protective equipment, including rigid helmets and padding, whereas junior rugby players are only required to wear a fitted mouth guard and any other protective equipment must be soft in order to reduce the risk of possible injury to other players through accidental contact to any part of the body.

When comparing the resultant rotational accelerations with youth American football players, the median rotational acceleration (2296 rad/ $\left./ \mathrm{sec}^{2}\right)$ was higher than the median and 95th percentiles reported for 7- to 8-year-old players $\left(686 \mathrm{rad} / \mathrm{sec}^{2} \text { and } 2052 \mathrm{rad} / \mathrm{sec}^{2} \text {, respectively) }\right)^{39}$ and 9- to 12-year-old players $\left(829 \mathrm{rad} / \mathrm{sec}^{2}\right.$ and $1884 \mathrm{rad} /$ $\mathrm{sec}^{2}$, respectively). ${ }^{6}$ When compared to 12 - to 14 -year-old players (987 $\mathrm{rad} / \mathrm{sec}^{2}$ and $2769 \mathrm{rad} / \mathrm{sec}^{2}$, respectively), ${ }^{11}$ high school players ${ }^{4,5}\left(903 \mathrm{rad} / \mathrm{sec}^{2}\right.$ and $2527 \mathrm{rad} / \mathrm{sec}^{2}$, respectively), and collegiate American football players ${ }^{9,34}$ (904-981 rad/ $/ \mathrm{sec}^{2}$ and 2787-2975 rad/ $/ \mathrm{sec}^{2}$, respectively), this was similar to the current study that recorded a higher median and 95th percentile $\left(9615 \mathrm{rad} / \mathrm{sec}^{2}\right)$ resultant rotational acceleration. This may be related to the type of activity undertaken in the junior rugby union, where players are required to tackle the player to the ground and use a different tackle technique, which may include a rotational type of movement that increases the rotational forces re-

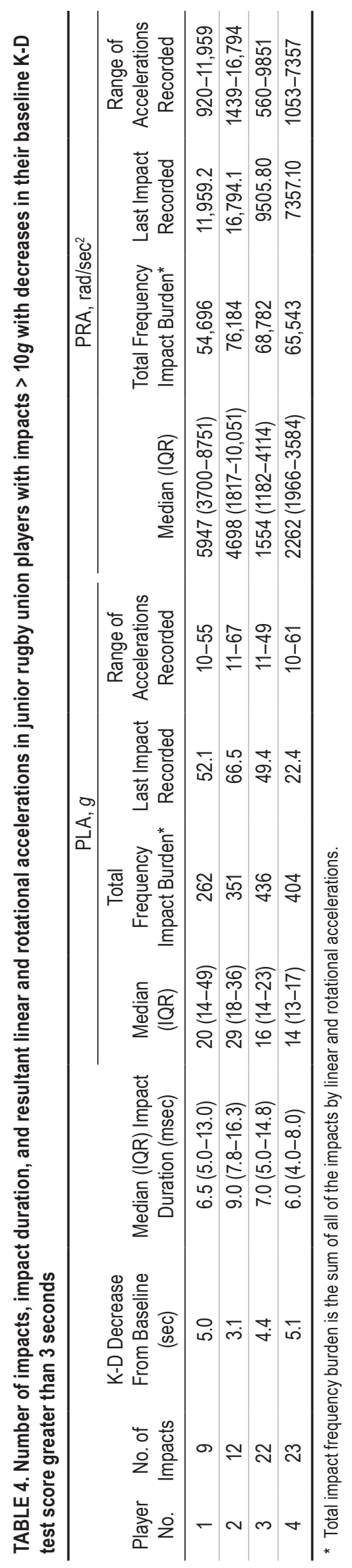


corded at the head. No other study has reported how the different tackle techniques seen in rugby union differ from tackles in American football, where the play ceases once the ball or the player carrying the ball is grounded. Further research is warranted to explore if these differences have an effect on the forces recorded at the head.

Another possible explanation for the differences observed may be the different biomechanical properties of the head and neck observed in children when compared with adults. ${ }^{27}$ Younger children have an increased headto-body ratio that can result in a higher center of gravity and increased head momentum. ${ }^{36}$ Children have less developed neck and shoulder musculature when compared with adults. ${ }^{32,36} \mathrm{~A}$ consequence of the higher head-to-body ratio, and the decreased neck and shoulder musculature, is the inability to dissipate impact forces that occur from match participation. Greater forces are required to cause similar concussive injuries in smaller brains than larger brains with greater mass..$^{15,32}$ As a result, children exhibiting the signs and symptoms of a concussion may have sustained greater forces than an adult presenting with similar signs and symptoms of a concussion. ${ }^{27}$

The current study reported the linear and rotational accelerations by the median (IQR) and 95th percentile results. These results were used for comparisons with limited previous studies that reporting on American Pop Warner, youth, and high-school football players. Other studies have used either a median and/or 95th percentile result format, or only reported linear accelerations, which has limited interstudy comparisons. This has resulted in the information provided by these studies being left to stand alone and await future studies that report similar data acquisition limits and formats in order to to enable comparisons to be completed.

As this was an evaluative study with only 4 matches observed, the results of this study must be interpreted with caution. No video recording was undertaken, as these participants were minors, and there was no way to verify what match activity resulted in the impact. The players in this evaluative study were all younger than age of 9 years, and the impact characteristics maybe specific to this age group. The head impact exposure experienced by this cohort of players may vary when compared with other junior rugby union players at different age levels, as the head impact exposure likely varies by age.

Although the XPatch has undergone some reported validation studies and has been compared with the Head Impact Telemetry System, the results have varied. The accelerometers used in this study have been reported to have a strong correlation with anterior-posterior translation $\left(r^{2}=0.93\right),{ }^{38}$ a normalized root square error of $18 \%$ for PLA with an overprediction of $15 \mathrm{~g} \pm 7 \mathrm{~g}$, and $2500 \pm$ $1200 \mathrm{rad} / \mathrm{sec}^{2}$ for PRA. ${ }^{38}$ Nevins et al. ${ }^{30}$ reported that the XPatch had good estimates of PLA but underestimated PRA by more than $25 \%$ and recorded more impacts than were visibly seen. If these studies were used to verify the magnitude and distribution of impacts to the head, then the cohort of players involved in this study may have recorded as few as $12 \pm 10$ impacts per player per game with a median resultant linear acceleration of $12 \mathrm{~g}$ (IQR $10 \mathrm{~g}-$ $17 \mathrm{~g}$ ), and rotational accelerations of between $1882 \mathrm{rad} / \mathrm{sec}^{2}$ (IQR 730-4387 $\mathrm{rad} / \mathrm{sec}^{2}$ ) (corrected for overprediction) and $9184 \mathrm{rad} / \mathrm{sec}^{2}$ (IQR 5416-16,607 $\mathrm{rad} / \mathrm{sec}^{2}$ ) (corrected for underprediction). Although we found these data, there are no consistent reliability studies for the XPatch, and the interpretation of these results should be undertaken with some caution.

\section{Conclusions}

Median linear acceleration measured over 4 matches in an under-9-year-old rugby union team was similar to the median linear accelerations reported in studies for American Pop Warner and Youth football. Median rotational accelerations were higher than American Pop Warner and Youth football. There is a need to standardize the reporting of head impact biomechanics in order to enable accurate comparisons across published studies.

\section{Acknowledgments}

We wish to thank the parents of the players who partook in the study, with special mention to Frania, Jamie, and Caleb.

\section{References}

1. Altman DG, Bland JM: Diagnostic tests. 1: Sensitivity and specificity. BMJ 308:1552, 1994

2. Broglio SP, Eckner JT, Martini D, Sosnoff JJ, Kutcher JS, Randolph C: Cumulative head impact burden in high school football. J Neurotrauma 28:2069-2078, 2011

3. Broglio SP, Schnebel B, Sosnoff JJ, Shin S, Fend X, He X, et al: Biomechanical properties of concussions in high school football. Med Sci Sports Exerc 42:2064-2071, 2010

4. Broglio SP, Sosnoff JJ, Shin S, He X, Alcaraz C, Zimmerman J: Head impacts during high school football: a biomechanical assessment. J Athl Train 44:342-349, 2009

5. Broglio SP, Surma T, Ashton-Miller JA: High school and collegiate football athlete concussions: a biomechanical review. Ann Biomed Eng 40:37-46, 2012

6. Cobb BR, Urban JE, Davenport EM, Rowson S, Duma SM, Maldjian JA, et al: Head impact exposure in youth football: elementary school ages 9-12 years and the effect of practice structure. Ann Biomed Eng 41:2463-2473, 2013

7. Crisco JJ, Chu JJ, Greenwald RM: An algorithm for estimating acceleration magnitude and impact location using multiple nonorthogonal single-axis accelerometers. J Biomech Eng 126:849-854, 2004

8. Crisco JJ, Fiore R, Beckwith JG, Chu JJ, Brolinson PG, Duma $S$, et al: Frequency and location of head impact exposures in individual collegiate football players. J Athl Train 45:549-559, 2010

9. Crisco JJ, Wilcox BJ, Beckwith JG, Chu JJ, Duhaime AC, Rowson S, et al: Head impact exposure in collegiate football players. J Biomech 44:2673-2678, 2011

10. Daniel RW, Rowson S, Duma SM: Head impact exposure in youth football. Ann Biomed Eng 40:976-981, 2012

11. Daniel RW, Rowson S, Duma SM: Head impact exposure in youth football: middle school ages 12-14 years. J Biomech Eng 136:094501-094506, 2014

12. Field M, Collins MW, Lovell MR, Maroon J: Does age play a role in recovery from sports-related concussion? A comparison of high school and collegiate athletes. J Pediatr 142:546-553, 2003

13. Galetta KM, Barrett J, Allen M, Madda F, Delicata D, Tennant AT, et al: The King-Devick test as a determinant of head trauma and concussion in boxers and MMA fighters. Neurology 76:1456-1462, 2011

14. Galetta KM, Brandes LE, Maki K, Dziemianowicz MS, Laudano E, Allen M, et al: The King-Devick test and sports- 
related concussion: study of a rapid visual screening tool in a collegiate cohort. J Neurol Sci 309:34-39, 2011

15. Goldsmith W, Plunkett J: A biomechanical analysis of the causes of traumatic brain injury in infants and children. Am J Forensic Med Pathol 25:89-100, 2004

16. Greenwald RM, Gwin JT, Chu JJ, Crisco JJ: Head impact severity measures for evaluating mild traumatic brain injury risk exposure. Neurosurgery 62:789-798, 2008

17. Guskiewicz KM, Mihalik JP, Shankar V, Marshall SW, Crowell DH, Oliaro SM, et al: Measurement of head impacts in collegiate football players: relationship between head impact biomechanics and acute clinical outcome after concussion. Neurosurgery 61:1244-1253, 2007

18. Hanlon EM, Bir CA: Real-time head acceleration measurement in girls' youth soccer. Med Sci Sports Exerc 44:11021108,2012

19. Harpham JA, Mihalik JP, Littleton AC, Frank BS, Guskiewicz KM: The effect of visual and sensory performance on head impact biomechanics in college football players. Ann Biomed Eng 42:1-10, 2014

20. Hopkins WG, Marshall SW, Batterham AM, Hanin J: Progressive statistics for studies in sports medicine and exercise science. Med Sci Sports Exerc 41:3-13, 2009

21. Hopkins WG, Marshall SW, Quarrie KL, Hume PA: Risk factors and risk statistics for sports injuries. Clin J Sport Med 17:208-210, 2007

22. King D, Hume PA, Brughelli M, Gissane C: Instrumented mouthguard acceleration analyses for head impacts in amateur rugby union players over a season of matches. Am J Sports Med 43:614-624, 2015

23. Krause LM, Naughton GA, Denny G, Patton D, Hartwig T, Gabbett TJ: Understanding mismatches in body size, speed and power among adolescent rugby union players. J Sci Med Sport 18:358-363, 2015

24. Landis JR, Koch GG: The measurement of observer agreement for categorical data. Biometrics 33:159-174, 1977

25. Lennon A: Measurement of Head Impact Biomechanics: A Comparison of the Head Impact Telemetry System and X2Biosystems XPatch [master's thesis]. Chapel Hill, NC: University of North Carolina, 2015

26. Leong DF, Balcer LJ, Galetta SL, Liu Z, Master CL: The King-Devick test as a concussion screening tool administered by sports parents. J Sports Med Phys Fitness 54:70-77, 2014

27. Meehan WP III, Taylor AM, Proctor M: The pediatric athlete: younger athletes with sport-related concussion. Clin Sports Med 30:133-144, x, 2011

28. Mihalik JP, Bell DR, Marshall SW, Guskiewicz KM: Measurement of head impacts in collegiate football players: an investigation of positional and event-type differences. Neurosurgery 61:1229-1235, 2007

29. Mihalik JP, Blackburn JT, Greenwald RM, Cantu RC, Marshall SW, Guskiewicz KM: Collision type and player anticipation affect head impact severity among youth ice hockey players. Pediatrics 125:e1394-e1401, 2010

30. Nevins D, Smith L, Kensrud J: Laboratory evaluation of wireless head impact sensor. Procedia Eng 112:175-179, 2015
31. Ocwieja KE, Mihalik JP, Marshall SW, Schmidt JD, Trulock SC, Guskiewicz KM: The effect of play type and collision closing distance on head impact biomechanics. Ann Biomed Eng 40:90-96, 2012

32. Ommaya AK, Goldsmith W, Thibault L: Biomechanics and neuropathology of adult and paediatric head injury. Br J Neurosurg 16:220-242, 2002

33. Pellman EJ, Viano DC, Tucker AM, Casson IR, Waeckerle JF: Concussion in professional football: reconstruction of game impacts and injuries. Neurosurgery 53:799-814, 2003

34. Rowson S, Duma SM, Beckwith JG, Chu JJ, Greenwald RM, Crisco JJ, et al: Rotational head kinematics in football impacts: an injury risk function for concussion. Ann Biomed Eng 40:1-13, 2012

35. Tjarks BJ, Dorman JC, Valentine VD, Munce TA, Thompson PA, Kindt SL, et al: Comparison and utility of King-Devick and ImPACT ${ }^{\circledR}$ composite scores in adolescent concussion patients. J Neurol Sci 334:148-153, 2013

36. Vopat L, Micheli L: Emergency care of the adolescent athlete, in McDonagh D, Ziderman D (eds): The IOC Manual of Emergency Sports Medicine. West Sussex, UK: Wiley Blackwell, 2015, pp 205-211

37. Wong RH, Wong AK, Bailes JE: Frequency, magnitude, and distribution of head impacts in Pop Warner football: the cumulative burden. Clin Neurol Neurosurg 118:1-4, 2014

38. Wu LC, Nangia V, Bui K, Hammoor B, Kurt M, Hernandez F, et al: In vivo evaluation of wearable head impact sensors. Ann Biomed Eng [epub ahead of print], 2015

39. Young TJ, Daniel RW, Rowson S, Duma SM: Head impact exposure in youth football: elementary school ages 7-8 years and the effect of returning players. Clin J Sport Med 24:416-421, 2014

40. Zhang L, Yang KH, King AI: A proposed injury threshold for mild traumatic brain injury. J Biomech Eng 126:226236,2004

\section{Disclosures}

The authors report no conflict of interest concerning the materials or methods used in this study or the findings specified in this paper.

\section{Author Contributions}

Conception and design: King, Hume, Clark. Acquisition of data: King, Gissane. Analysis and interpretation of data: King, Hume, Gissane. Drafting the article: all authors. Critically revising the article: all authors. Reviewed submitted version of manuscript: all authors. Approved the final version of the manuscript on behalf of all authors: King. Statistical analysis: King, Gissane.

\section{Correspondence}

Doug King, Emergency Department, Hutt Valley District Health Board, Private Bag 31-907, Lower Hutt, New Zealand. email: dking@aut.ac.nz. 